\title{
Contraceptive prevalence and preference in a cohort of south-east Nigerian women
}

\author{
This article was published in the following Dove Press journal: \\ Patient Preference and Adherence \\ 25 May 2015 \\ Number of times this article has been viewed
}

John Okafor Egede'

Robinson Chukwudi Onoh'

Odidika Ugochukwu

Joannes Umeora'

Chukwuemeka Anthony

lyoke ${ }^{2}$

Ikechukwu Benedict

Okechukwu Dimejesi'

Lucky Osaheni Lawani'

'Department of Obstetrics and Gynecology, Federal Teaching Hospital, Abakaliki, Ebonyi State, Nigeria; ${ }^{2}$ Department of Obstetrics and Gynaecology, University of Nigeria Teaching Hospital, Ituku-Ozalla, Enugu, Nigeria
Correspondence: Robinson Chukwudi Onoh

Department of Obstetrics and Gynecology, Federal Teaching Hospital, Pmb 102, Abakaliki, Ebonyi State, 48000 I Nigeria

Tel +2348037007519

Email drrobonoh@gmail.com
Background: Rates of fertility, population growth, and maternal deaths in Nigeria are among the highest in the world, with an estimated $4 \%$ of all births being unwanted and $7 \%$ mistimed. These are caused mainly by nonuse, inappropriate choice, and difficulty in accessing contraceptive commodities. The purpose of this study was to determine the prevalence and factors influencing the choice and sources of contraceptive options among market women in Ebonyi State, Nigeria.

Methods: This was a questionnaire-based, cross-sectional, descriptive study involving 330 market women of reproductive age in Abakaliki, Ebonyi State, Nigeria. A survey was carried out to identify their knowledge, use, and sources of contraception and the factors that influence their contraceptive practices.

Results: Knowledge of contraception was high (275 [83.3\%]), and 229 (69.4\%) of the study population approved of contraceptive use. However, only 93 (28.3\%) of the respondents were currently using any form of contraception. Fifty-four women (16.3\%) were using modern methods. The commonly used forms of modern contraception were the barrier method (male condoms, $27[8.2 \%])$, the oral contraceptive pill (10 [3.0\%]), injectables (8 $[2.5 \%])$, and the intrauterine contraceptive device (7 [2.0\%]). The most common source of contraceptive products was patent medicine dealers (58 [51\%]). The main barriers to use of contraception were desire for more children (86 [26.1\%]), religious prohibition (62 [18.8\%]), spousal disapproval (32 [9.7\%]), and the perceived side effects of modern contraceptives (25 [7.6\%]). There was a significant association for approval of contraception when the model was adjusted for religion (odds ratio [OR] 0.39, 95\% confidence interval [CI] 0.18-0.84; $P=0.02$ ); educational status (OR 2.84, 95\% CI 0.96-8.40; $P=0.04$ ); parity (OR 1.78, 95\% CI 1.09-2.85; $P=0.03$ ); and social class (OR 2.54, 95\% CI 1.26-5.11; $P=0.01$ ).

Conclusion: There is good knowledge about contraception among Nigerian women, but use of these products is low. The main barriers to use of contraception are the desire for more children, religious prohibition, and spousal disapproval.

Keywords: barrier method, contraceptive methods, market women, Nigeria, prevalence

\section{Introduction}

Unexpected or unplanned pregnancy poses a major public health challenge for women of reproductive age, especially in developing countries. ${ }^{1}$ It is estimated that approximately 210 million pregnancies occur annually worldwide, with 80 million (38\%) being unplanned and 46 million (22\%) ending in abortion. ${ }^{2}$ Nigeria, with a population close to 160 million, an estimated national growth rate of $3.2 \%$, and a total fertility rate of 5.7 and 6.3 in urban and rural areas, respectively, has an estimated maternal death rate of 545 per 100,000 live births and 6.8 million pregnancies annually, of which $16 \%$ end in spontaneous miscarriage and $11 \%$ in induced abortion. ${ }^{3,4}$ Overall, $4 \%$ of all births in Nigeria are unwanted, while $7 \%$ are mistimed (wanted later). ${ }^{3}$ More than 200 million women in developing countries would like to delay their next pregnancy or even stop 
bearing children altogether, ${ }^{5}$ but many still rely on traditional and less effective methods of contraception or no methods at all. Barriers to use of more effective modern contraceptive options include lack of awareness, lack of access, cultural factors, religion, opposition to use by partners or family members, fear of risks and side effects of contraceptives, educational level, and socioeconomic status of the woman. ${ }^{5-9}$

The contraceptive prevalence rate is related to the maternal mortality rate, and it has been shown that countries with a low prevalence of contraception have high maternal mortality rates. ${ }^{10,11}$ In industrialized countries, virtually all married women use contraception at some time in their reproductive lives, with contraception viewed as a basic right of women and most women are armed with the information, education, and means to use it. In contrast, the proportion reporting such use in developing countries is extremely low. ${ }^{8,12}$

Studies have demonstrated that there is widespread knowledge of contraceptive options in Nigeria. ${ }^{1,3,7,13}$ Despite this awareness, the contraceptive prevalence rate among women in the reproductive age group is only $15 \%,{ }^{3}$ although approximately $29 \%$ of all currently married women reported using a family planning method at some point in their lifetime. ${ }^{3}$

Modern contraceptives are available in different forms, ie, oral contraceptive pills, foaming tablets, creams, jelly, injectables, implants, intrauterine devices, and barrier methods (in the form of condoms for males and females), as well as permanent surgical methods. The focus of most family planning programs is on promoting adoption of modern contraceptive methods. The availability and use of appropriate contraceptive methods for family planning are important in controlling population growth and other complications of pregnancy., ${ }^{4,14}$ Appropriate methods for couples and individuals vary according to age, parity, family size preference, and level of awareness, as well as the cultural and religious acceptability of the methods available. ${ }^{12,15}$ Ability to choose among the range of methods available is central to the practice of contraception. ${ }^{16}$ Substantial evidence indicates that limited choice of contraceptive methods limits the opportunity for couples to choose a method that suits their needs, resulting in lower levels of contraceptive prevalence. ${ }^{17}$ Thus, the availability of a wide range of contraceptive options affords users the ability to make active, free, and informed choices. ${ }^{15,16}$

For many people, decision-making concerning fertility control is a deeply personal and sensitive issue, often involving religious and philosophical convictions, and the choice of a modern method is a complex sociological issue, especially among African women. ${ }^{14,18,19}$ Many women are reluctant to accept an artificial method of contraception, and those unwilling to do so view children as a source of support in old age. This is even more important in Ebonyi State, which is a largely agrarian community. Knowledge of clients' source of contraceptives and preferences can help to ensure that commodities are provided where they are most likely to be accepted. The source of contraceptives can limit the number of available methods as well as the type of information clients receive on the method chosen. Incorrect information leads to unsatisfactory use, which can lead to high discontinuation and failure rates.

This research is intended to bring into focus the prevalence, choices, and sources of contraceptive options among market women of reproductive age in Ebonyi State, Nigeria, and to determine the awareness and use of contraception among these women.

\section{Materials and methods}

This was a questionnaire-based, cross-sectional, descriptive study of market women in Abakaliki, the capital city of Ebonyi State, one of the five south-eastern states in Nigeria. Abakaliki is located between latitude $6.3^{\circ} \mathrm{N}$ and longitude $8.1^{\circ} \mathrm{E}$. It is an urban city and made up of two local government areas, ie, Abakaliki and Ebonyi. It has a total population of 276,909, with women comprising 144,003 of this population. ${ }^{3}$ The indigenous inhabitants are mainly agrarian. The Abakpa market is the largest in the state, and is situated in the heart of the city. It is a busy daily market, with a trade union association that regulates and maintains harmonious coexistence among its members. The market is well planned and has lock-up shops arranged in lines in which the traders display their wares.

The study group included women within the reproductive age group of 14-49 years drawn from the Abakpa market in Abakaliki. One in every three shops that was owned by a woman was approached for the study. Informed consent was obtained from those willing to participate, after which a questionnaire was administered. The research assistant guided the participants in the research questions, and those who could not understand English were assisted by a research assistant who could understand the local dialect. The research assistants were female house officers or registrars in obstetrics and gynecology at the time of the study. A total of six research assistants were recruited and appropriately trained. Women who were not sexually active, postmenopausal, or refused to give their consent were excluded from the study.

The sample size recruited for this study was determined using the formula devised by $\mathrm{Kish}^{20}$, and calculated a size of 275 ; this was increased by $20 \%$ to ensure an adequate 
sample, giving a sample size of 330. This number is adequate to accommodate attrition and omissions during the study.

After permission was obtained from the institutional research and ethics committee, the questionnaires were administered by the trained research assistants, and the information obtained was recorded on the questionnaire. The data collected included age, parity, educational status, occupation and educational status of the husbands, as well as the respondent's knowledge of contraceptives, their current choice, and its source.

The data obtained were entered into a computer using 2008 Epi Info ${ }^{\mathrm{TM}}$ statistical software (version 3.5.1, Centers for Disease Control, Atlanta, GA, USA). Univalent and bivalent analyses were used to generate values for assessment of descriptive variables.

\section{Results}

A total of 342 sexually active women were interviewed, and $330(96.5 \%)$ responded to all items in the questionnaire, giving a response rate of $96.5 \%$. The remaining $5.5 \%$ abandoned the study, making the excuse of needing to attend to a customer, being too tired, or needing to keep their contraceptive arrangements secret. The majority of the respondents (305 [92.4\%]) were married, while four $(1.2 \%)$ each were widows or divorcees, two (0.6\%) were separated, and $15(4.5 \%)$ were single. Among the married couples, 283 (92.7\%) were in a monogamous relationship, while $22(7.3 \%)$ were in a polygamous family setting. Only six (1.8\%) was younger than 20 years at the time of interview, $170(51.5 \%)$ were younger than 30 years, and 54 (16.4\%) were 40 years of age or older. Most of the respondents had one to four children (168 [50.9\%]), 105 (31.8\%) had more than five children, and 57 (17.3\%) were yet to have children at the time of the interview. The majority had secondary school education (171 [51.8\%]), 90 (27.6\%) had tertiary education, and $55(16.7 \%)$ and $14(4.2 \%)$ had primary education and no formal education, respectively. Abakaliki is mainly inhabited by Ibos and Christians; the majority of the respondents were Ibos (321 [97.3\%]) and 315 (95.5\%) were Christians. Of the Christians, 182 (55.2\%) were Roman Catholics, 74 (22.7\%) were Pentecostal, and 68 (20.6\%) were Protestants. Islamic and traditional religion accounted for four $(1.2 \%)$ and two $(0.2 \%)$ women, respectively. Most of the respondents were of low social class; (131 [39.8\%]), 77 (23.3\%), and 62 (18.8\%) were class IV, III, and V, respectively (Table 1). Table 2 shows the adjusted odds ratios (ORs) for approval of contraception according to sociodemographic variables. There was a significant association when the model was adjusted for religion (OR 0.39, 95\% confidence interval [CI] 0.18-0.84;
$P=0.02)$; educational status (OR 2.84, 95\% CI 0.96-8.40; $P=0.04$ ); parity (OR 1.78, 95\% CI 1.09-2.88; $P=0.03$ ); and social class (OR 2.54, 95\% CI 1.26-5.11; $P=0.01$ ).

There was high awareness of contraceptives among the respondents (275 [83.3\%]), but 55 women (16.7\%) had never heard of contraceptives. More than half of those who were aware knew that the purpose of contraception was to prevent pregnancy, for child spacing, and for prevention of sexually transmitted diseases. The main sources of information on options for contraception were friends (128 [33.8\%]), health workers (100 [30.3\%]), and fellow market women and church members (67 [20.3\%] for each). Other sources of information included electronic media (56 [17.0\%]), neighbors (13 [3.9\%]), relatives (10 [3.0\%]), and print media (92.7\%, Table 3).

Only $229(69.4 \%)$ of the respondents approved of use of contraceptives, and $101(30.6 \%)$ did not. The most common reasons for approval were improvement in health (100 [30.3\%]), maintenance of a smaller family size (98 [29.7\%]), and the fact that it made life more comfortable (51 [15.5]). The most common reasons for disapproval were perceived harmfulness of modern contraceptives (46 [13.9\%]), religious prohibition (40 [12.7\%]), and husband's disapproval (12 [3.6\%]). Other reasons for disapproval included contraception not being supported by government (11 [3.3\%]), personal perception (8 [2.4\%]), an abortifacient effect (6 [1.8\%]), and a perception that its use may encourage promiscuity (5 [1.5\%], see Table 4).

Table 5 shows the reasons for choosing a contraceptive method, discontinuation of a chosen method, and not using any method of contraception. The most common reasons for choice of a contraception option were personal choice (70 [21.1\%]), approval of the husband (41 [12.4\%]) recommendation by friends (18 [5.5\%]), low cost (14 [4.2\%]), safety of a particular method (3 [0.9\%]), and religious approval (2 [0.6\%]). The major reason for discontinuation of a contraceptive method was the desire for more children (37 [11.2\%]). Other reasons included spousal disapproval (30 [9.1\%]), side effects (24 [7.3\%]), religious beliefs (7 [2.1\%]), and cultural beliefs $(2[0.6 \%])$. The most common reason for not using any form of contraception included desire for more children (86 [26.1\%]), religion prohibition (62 [18.8\%]), husband's disapproval (32 [9.7\%]), and fear of adverse side effects (25 [7.6\%]). Other reasons related to cultural belief and the risk of an abortifacient effect (9 [2.7\%] each), as well as cost, personal wishes, and no identifiable reason.

Figure 1 shows the awareness, use, and prevalence of contraceptive options in the study population. Barrier methods (215 [65.2\%]), pills (139 [42.1\%]), and injectables 
Table I Sociodemographic characteristics of the study population

\begin{tabular}{|c|c|c|c|}
\hline Variables & $\begin{array}{l}\text { Number (total 330), } \\
\text { n (\%) }\end{array}$ & $\begin{array}{l}\text { Approved of contraception, } \\
\mathbf{n}(\%)\end{array}$ & $\begin{array}{l}\text { Disapproved of } \\
\text { contraception, } \mathbf{n}(\%)\end{array}$ \\
\hline \multicolumn{4}{|l|}{ Age (years) } \\
\hline$\leq 19$ & $6(1.8)$ & $4(66.7)$ & $2(33.3)$ \\
\hline $20-24$ & $80(24.2)$ & $53(66.2)$ & $27(33.8)$ \\
\hline $25-29$ & $84(25.5)$ & $63(75)$ & $21(25)$ \\
\hline $30-34$ & $82(24.9)$ & $54(65.9)$ & $28(34.1)$ \\
\hline $35-39$ & $24(7.3)$ & $14(58.3)$ & $10(4 I .7)$ \\
\hline$\geq 40$ & $54(16.4)$ & $33(61.1)$ & $21(38.9)$ \\
\hline \multicolumn{4}{|l|}{ Parity } \\
\hline 0 & $57(17.3)$ & 45 (78.9) & $12(21.1)$ \\
\hline $1-4$ & $168(50.9)$ & $115(68.5)$ & $53(31.5)$ \\
\hline$\geq 5$ & $105(31.8)$ & $61(58.1)$ & $44(41.9)$ \\
\hline \multicolumn{4}{|l|}{ Marital status } \\
\hline Married & $305(92.4)$ & $201(86.7)$ & $104(34.1)$ \\
\hline Divorced & $4(1.2)$ & $3(75)$ & I (25) \\
\hline Widow & $4(1.2)$ & $2(50)$ & $2(50)$ \\
\hline Separated & $2(0.6)$ & $2(100)$ & $0(0)$ \\
\hline Single & $15(4.5)$ & $13(86.7)$ & $2(13.3)$ \\
\hline \multicolumn{4}{|l|}{ Educational status } \\
\hline No formal education & 14 (4.2) & $6(42.9)$ & $8(57.1)$ \\
\hline Primary & $55(16.7)$ & $30(54.5)$ & $25(45.5)$ \\
\hline Secondary & $|7|(5 \mid .8)$ & $107(62.6)$ & $64(37.4)$ \\
\hline Tertiary & $90(27.2)$ & $78(86.7)$ & $12(13.3)$ \\
\hline \multicolumn{4}{|l|}{ Religion } \\
\hline Roman Catholic & $182(55.2)$ & III (6I) & 7I (39) \\
\hline Protestant & $68(20.6)$ & $50(73.5)$ & $18(26.5)$ \\
\hline Pentecostal & 74 (22.7) & $55(74.3)$ & $19(25.7)$ \\
\hline Islamic & $4(1.2)$ & $4(100)$ & $0(0)$ \\
\hline Traditional & $2(0.2)$ & I (50) & I (50) \\
\hline \multicolumn{4}{|l|}{ Social class } \\
\hline 1 & $14(4.2)$ & 10 (7I.4) & $4(28.6)$ \\
\hline II & $46(3.9)$ & $39(84.8)$ & $7(15.2)$ \\
\hline III & $77(23.3)$ & $48(62.3)$ & 29 (37.7) \\
\hline IV & |3| (39.8) & 89 (67.9) & $42(32.1)$ \\
\hline$\vee$ & $62(18.8)$ & $35(56.5)$ & $27(43.5)$ \\
\hline
\end{tabular}

(99 [30.1\%]) were the most popular contraceptive methods among the respondents, while the least popular was surgery, ie, bilateral tubal ligation (32 [9.7\%]). The most popular practices were the Billings ovulation method (72 [21.8\%]), particularly among Roman Catholics, and periodic abstinence (60 [18.2\%]). More than half of the respondents were aware of more than one method, especially those who received their information from health workers.

The contraceptive options most commonly used included barrier methods (111 [33.6\%]), pills (28 [8.5\%]), and injectables 19 [5.8\%]). The other contraceptive options ever used included periodic abstinence and the Billings method (20 [6.1\%] each) as well as lactational amenorrhea (8 [2.4\%]), an implant, and bilateral tubal ligation (2 [0.6\%] each). Contraceptive prevalence was low at $28.3 \%$ for all methods and $16.3 \%$ for modern methods. The most common modern methods practiced were the barrier method (27 [8.2\%]), pills (10 [3.0\%]), injectables (9 [2.5\%]), and intrauterine contraceptive device (7 [2.0\%]), while the traditional methods most commonly used included the Billings method (11 [3.3\%]), periodic abstinence (10 [3.0\%]), and withdrawal (10 [3.0\%]).

Figure 2 shows that most of the respondents who were using one form of modern contraceptive or another obtained supplies from the patent medicine dealer (58 [51\%]), family planning clinic (25 [22\%]), private hospital (15 [13\%]), public hospital (10 [9\%]), or open market (6 [5\%]).

\section{Discussion}

In this study, contraceptive awareness was $83.3 \%$ and approval of contraception was $63.3 \%$, while contraceptive prevalence for all methods was $28.3 \%$ and for modern methods was $16.3 \%$. This shows that awareness of contraceptive 
Table 2 Relationship between sociodemographic variables and approval of use of contraception

\begin{tabular}{|c|c|c|c|c|}
\hline Variable & $\begin{array}{l}\text { Approval } \\
\text { of contraception }\end{array}$ & $\begin{array}{l}\text { Disapproval } \\
\text { of contraception }\end{array}$ & OR (95\% Cl) & $P$-value \\
\hline \multicolumn{5}{|l|}{ Age (years) } \\
\hline$<30$ & $120(36.4)$ & $50(15.1)$ & & \\
\hline$\geq 30$ & I0I (30.6) & $59(17.9)$ & $1.40(0.89-2.22)$ & 0.19 \\
\hline \multicolumn{5}{|l|}{ Parity } \\
\hline$\leq 4$ & I $60(48.5)$ & 65 (19.7) & & \\
\hline$>4$ & $61(18.5)$ & $44(13.33)$ & $1.78(1.09-2.88)$ & $0.03 *$ \\
\hline \multicolumn{5}{|l|}{ Marital status } \\
\hline Married & 201 (60.9) & 104 (3I.5) & & \\
\hline Unmarried & $20(6.1)$ & $5(1.5)$ & $0.48(0.18-1.32)$ & 0.22 \\
\hline \multicolumn{5}{|l|}{ Educational status } \\
\hline Educated & $215(65.2)$ & I0I (30.6) & & \\
\hline Uneducated & $6(1.8)$ & $8(2.4)$ & $2.84(0.96-8.40)$ & $0.04 *$ \\
\hline \multicolumn{5}{|l|}{ Religion } \\
\hline Roman Catholic & $111(6 I)$ & 7I (39) & & \\
\hline Other & $110(74)$ & $38(26)$ & $0.39(0.18-0.84)$ & $0.02 *$ \\
\hline \multicolumn{5}{|l|}{ Social class } \\
\hline$\leq 2$ & $49(14.9)$ & II (3.3) & & \\
\hline$>2$ & $172(52.1)$ & $98(29.7)$ & $2.54(\mathrm{I} .26-5.1 \mathrm{I})$ & $0.01 *$ \\
\hline
\end{tabular}

Notes: *Statistically significant. Values are shown as the number (percentage), unless otherwise stated. Those $<30$ years of age were I.40 times more likely to use contraception than those $\geq 30$ years of age (not statistically significant); those who were $\leq$ parity 4 were 1.78 times more likely to use contraception than those who were more than parity 4 (statistically significant); those who were married were less than half ( 0.48 times) as likely to use contraception (not statistically significant); those who were educated were more than twice (2.84) as likely to use contraception than those who were uneducated (statistically significant); those who were Roman Catholics were 0.39 times less likely to use contraception (statistically significant); those who were of higher social class, ie, $\leq 2$ were more than twice (2.54) as likely to use contraception than those of lower social class (statistically significant).

Abbreviations: $\mathrm{OR}$, odds ratio; $\mathrm{Cl}$, confidence interval.

options and approval of use did not translate into actual use. Some of the identified barriers to use of contraceptives, particularly modern methods, include perceived harmfulness, religious prohibition, husband's disapproval, and desire for more children. This high and widespread awareness but low utilization is consistent with some of the other studies done elsewhere in the country. ${ }^{1-3,13}$

The most common source of information about contraception was friends. Others were through health workers, churches and fellow women, neighbors, media (both electronic and print), and relatives. Although Olugbenga Bello et $\mathrm{al}^{8}$ found that health workers were the most common source of information, our study did not establish this. However,

Table 3 Sources of information about contraceptive methods

\begin{tabular}{lll}
\hline $\begin{array}{l}\text { Source of } \\
\text { information* }\end{array}$ & $\begin{array}{l}\text { Number } \\
\text { (total 330) }\end{array}$ & Percentage \\
\hline Friends & 128 & 38.8 \\
Health personnel & 100 & 30.3 \\
Fellow market women & 67 & 20.3 \\
Church & 67 & 20.3 \\
Electronic media & 56 & 17.0 \\
Relatives & 10 & 3.0 \\
Print media & 9 & 2.7
\end{tabular}

Note: *Multiple entries allowed. our findings in this regard are in keeping with other studies reporting friends to be the leading source of information for contraceptive use. ${ }^{1-3}$ Unfortunately, information obtained from friends is more likely to be incorrect and contain a lot of misinformation, distortion, falsehoods, and misconception, and may be self-centered. ${ }^{21}$

Table 4 Reasons for approval and disapproval of contraception

\begin{tabular}{lll}
\hline Variable* $^{*}$ & $\begin{array}{l}\text { Number } \\
\text { (total 330) }\end{array}$ & Percentage \\
\hline Reasons for disapproval & & \\
$\quad$ Contraceptives are harmful & 46 & 13.9 \\
Religious & 40 & 12.7 \\
Husband's disapproval & 12 & 3.6 \\
No government support & $1 \mathrm{I}$ & 3.3 \\
Personal reasons & 8 & 2.4 \\
Contraceptives are abortifacient & 6 & 1.8 \\
Encourages promiscuity & 5 & 1.5 \\
Reasons for approval & & \\
Improves health & 100 & 30.3 \\
Need for small family size & 98 & 29.7 \\
Fertility control & $8 \mathrm{I}$ & 24.5 \\
Ensure a comfortable lifestyle & $5 \mathrm{I}$ & 15.5 \\
Prevents STls & 6 & 1.8 \\
Personal reasons & 2 & 0.6 \\
\hline
\end{tabular}

Note: *Multiple entries allowed.

Abbreviation: STIs, sexually transmitted infections. 
Table 5 Reasons for choosing, discontinuing, or not choosing any form of contraception

\begin{tabular}{lll}
\hline Variable* & $\begin{array}{l}\text { Number } \\
\text { (total 330) }\end{array}$ & Percentage \\
\hline Reasons for choosing some form of contraception & 70 & 21.2 \\
Personal choice & 41 & 12.4 \\
Husband's approval & 18 & 5.5 \\
Recommendation by another woman & & \\
who had used the method & 14 & 4.2 \\
Affordable cost & 3 & 0.9 \\
Safety of a particular method & 2 & 0.2 \\
Approval by religion & & \\
Reasons for discontinuation & 37 & 11.2 \\
Desire for more children & 30 & 9.1 \\
Husband's disapproval & 24 & 7.3 \\
Side effects & 7 & 2.1 \\
Religious beliefs & 2 & 0.6 \\
Cultural beliefs & & \\
Reasons for not using contraception & 86 & 26.1 \\
Desire for more children & 62 & 18.8 \\
Religious beliefs & 32 & 9.7 \\
Husband's disapproval & 25 & 7.6 \\
Side effect & 11 & 3.3 \\
No know reason & 9 & 2.7 \\
Causes abortion & 9 & 2.7 \\
Cultural belief & 3 & 0.9 \\
Personal wishes & 2 & 0.6 \\
Cost & & \\
\hline Not & &
\end{tabular}

Note: *Multiple entries allowed.
We found that the contraceptive most commonly used currently is the barrier method (male condom). This does not concur with the 2008 National Demographic Survey, where injectables were the most predominantly used. ${ }^{3}$ Also, this did not agree with the work done by Ozumba et al and Ikechebelu et al which found the intrauterine contraceptive device to be the most commonly used. ${ }^{1,13,19}$ The human immunodeficiency virus/acquired immune deficiency syndrome awareness campaign may have contributed to the barrier method being the commonly used option in this study. Level of education also played an important role in approval and use of contraception, as the majority of the market women gave their highest level of education as primary, secondary or no formal education. This is very important because better education has been recognized as a critical factor in increasing the prevalence of contraception. ${ }^{21}$ This is in line with our finding that educational level has a significant association with the approval and utilization of contraception.

The most common source of contraceptive products identified was patent medicine dealers. This finding is in keeping with the 2008 National Demographic Survey, which reported that users of contraceptives sourced them mainly from the private sector. However, it is in contrast with Tanzania and

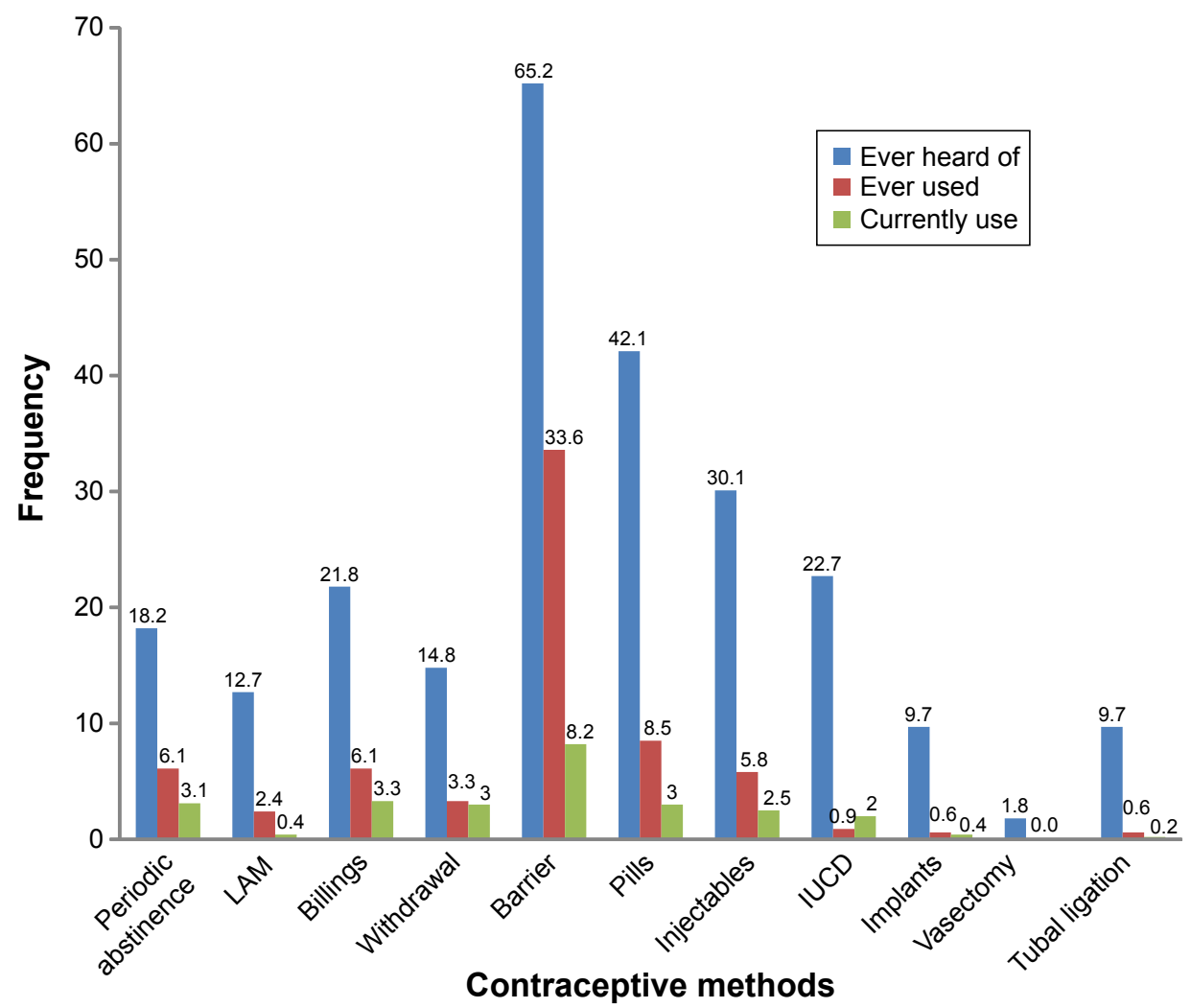

Figure I Contraceptive awareness, use, and prevalence.

Note: Barrier represents the male condom.

Abbreviations: IUCD, intrauterine contraceptive device; LAM, lactational amenorrhea method. 


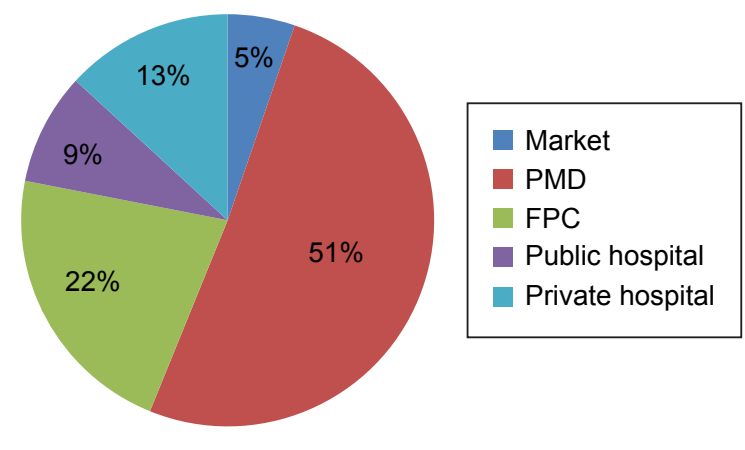

Figure 2 Sources of contraception.

Abbreviations: PMD, patent medicine dealer; FCP, family planning clinic.

Zimbabwe, where the government provides free family planning services. However, it is in agreement with a report by Oye-Adeniran et al who found that patent medicine shops were the most patronized, which is similar to practices in Ghana and Kenya. ${ }^{9,16}$ The most common reason for choice of source of contraception was ease of accessing the product and the protection of confidentiality, given that some women were using contraception without their husband's knowledge or approval. The choice of contraceptive source also depended on the type used. Those using injectables, an intrauterine device, or tubal ligation were more likely to obtain their supplies from a public or private hospital or a family planning clinic, while those using barrier methods or pills were more likely to source them from the patent medicine dealer's shop. Another study reported similar findings. ${ }^{16}$

Understanding the sources of contraceptive commodities and preferences of users is a helpful tool for delivery of a family planning service, and is required by program managers for strategic planning purposes to address areas of deficiencies and promote effective use of the methods. The 2008 Nigerian Demographic and Health Survey showed that $23 \%$ of users of contraceptives obtained them privately, $12 \%$ sourced them from government hospitals, and 13\% from other sources, including markets. ${ }^{3}$ This is consistent with findings in Ghana and Kenya, but in contrast with those in Zimbabwe and Tanzania, where there is strong government involvement in provision of family planning services. ${ }^{1,9,16,22,23}$

It has been shown that people in Nigeria are more likely to patronize patent medicine shops, which are widely available in the country, as their source of contraception. This is even more the case for married women, who are less likely to be culturally accepted in conventional government-run family planning clinics. ${ }^{3,16}$ In this study, religion has a significant association with contraception acceptance and use. Religion and Christian denomination have also been found to influence contraceptive use and source of purchase. ${ }^{16,21}$ Catholics and Muslims are more likely to patronize patent medicine shops because of the strong disapproval of contraception among these religious groups. ${ }^{21}$

In conclusion, more education and campaigning is still needed to improve the presently low prevalence and utilization of contraception in Ebonyi State.

\section{Recommendations}

Accessibility, availability, and ultimately acceptance of modern contraception can be achieved in Nigeria if there is significant investment in education and training of more family planning providers and volunteers, making family planning clinics more available, and providing a wide range of modern contraceptive options in these clinics. This will increase contraceptive prevalence and reduce the maternal health crises prevalent in sub-Saharan Africa, especially Nigeria.

Involvement of men in the campaign would help to overcome their objection to contraception for women. Provision of more options and political will to provide these commodities free or at a reduced cost may help to encourage our women to appreciate the importance of contraception and source them from appropriate places.

\section{Limitations}

This study was conducted in the capital of Ebonyi State, and may not completely reflect the true situation in the communities and villages across this state. Further, although the respondents expressed their opinions on contraception, the truthfulness of their answers could not be ascertained. However, considerable effort was made to present the topic and questionnaire as simply as possible.

\section{Acknowledgments}

The authors wish to express their gratitude to the executives of the trade union association in Abakaliki, Ebonyi State, Nigeria, for giving them the opportunity to conduct this research among the market women. The authors also thank their research assistants and all those who assisted them with secretarial work and data analysis.

\section{Disclosure}

The authors report no conflicts of interest in this work.

\section{References}

1. Monjok E, Smensy A, Ekabua JE, Essien EJ. Contraceptive practices in Nigeria: literature review and recommendation for future policy decisions. Open Access Journal of Contraception. 2010;1:9-22.

2. Guttmacher Institute. Sharing Responsibility: Women, Society and Abortion Worldwide. New York, NY, USA: Guttmacher Institute; 1999.

3. National Population Commission Nigeria and ICF Macro. Nigeria Demographic and Health Survey 2008. Calverton, MD, USA; 2009. Available from: http://dhsprogram.com/pubs/pdf/fr222/fr222.pdf. Accessed April 26 2015 . 
4. Kalu AC, Umeora OU, Adeoye SI. Experiences with provision of postabortion care in a university teaching hospital in a South-East Nigeria: a five year review. Afr J Reprod Health. 2012;16:105-112.

5. Singh S, Darroch JE, Vlassoff M, Nadeau J. Adding It Up: The Benefits of Investing in Sexual and Reproductive Health. New York NY, USA: Guttmacher Institute; 2003.

6. Carr D, Khan M. The Unfinished Agenda: Meeting the Needs for Family Planning in Less Developed Countries. Washington, DC, USA: Population Reference Bureau; 2004.

7. Adinma JI, Agbai AO, Nwosu BO. Contraceptive choices among Nigerian women attending an antenatal clinic. Adv Contracept. 1996; $14: 131-145$.

8. Olugbenga-Bello AI, Abodunrin OL, Adeomi AA. Contraceptive practices among women in rural communities in South-Western Nigeria. Global Journal of Medical Research. 2011;11:1-9.

9. Barrett J, Buckley C. Constrained contraceptive choices: IUD prevalence in Uzbekistan. Int Fam Plan Perspect. 2007;33:50-57.

10. United Nations Department of Social and Economic Affairs. Charting the progress of populations; contraceptive prevalence. United Nations Population Division; 2010. Available from: http://www. un.org/en/development/desa/population/publications/trends/progressof-populations.shtml. Accessed April 30, 2015.

11. Okonofua F. Need to intensify safe motherhood interventions in Africa. Afr J Reprod Health. 2003;7:7-12.

12. Report of the International Conference on Population and Development. Cairo, 5-13 September 1994; [Principle 8 of ICPD Program of Action]. United Nations Population Information Network. Available from: http:// www.un.org/popin/icpd/conference/offeng/poa.html. Accessed April $30,2015$.

13. Ikechebelu JI, Joe-Ikechebelu NN, Obiajulu FN. Knowledge, attitude and practice of contraceptives among Igbo women of south-east Nigeria. J Obstet Gynaecol. 2005;25:792-795.
14. Johnson-Hanks J. Time and social context of fertility. Population and Development Review. 2002;28:229-249.

15. United Nations Population Fund. Program of action adopted at the International Conference on Population and Development, Cairo. New York, NY, USA: United Nations Population Fund; 1996. Available from: http://www.un.org/popin/icpd5.htm. Accessed April 30, 2015.

16. Oye-Adeniran BA, Adewole IF, Umoh AV, et al. Sources of contraceptive commodities for user in Nigeria. PLoS Med. 2005;2:e306.

17. Ross J, Hardee K, Mumford E, Eids S. Contraceptive method choice in developing countries. Int Fam Plann Persp. 2001;28:32-40.

18. Burkman RT. Clinical pearls: factors affecting reported contraceptive efficacy rates in clinical studies. Int J Fertil Womens Med. 2002; 47:153-161.

19. Ozumba BC, Ibekwe PC. Contraceptive use at the family planning clinic of the University of Nigeria Teaching Hospital, Enugu, Nigeria. Public Health. 2001;115:51-53.

20. Kish L. Survey Sampling. New York, London; Wiley \& Sons, Inc.; 1965.

21. Oyedokun AO. Determinants of contraceptive usage: lessons from women in Osun State, Nigeria. Int J Humanit Soc Sci. 2007;1:1-14.

22. Federal Ministry of Health. The national reproductive health policy and strategy to achieve quality reproductive and sexual health for all Nigerians. Abuja, Nigeria; 2001. Available from: http://www. youth-policy.com/Policies/Nigeria $\% 20$ National $\% 20$ Reproductive $\% 20$ Health\%20Policy\%20and\%20Strategy.pdf. Accessed April 16, 2015.

23. Measure Communications. Unmet need for family planning: recent trends and their implications for programs. Available from: http://.www. prb.org/pdf/unmetneedfamplan-Eng.pdf. Accessed April 30, 2012.
Patient Preference and Adherence

\section{Publish your work in this journal}

Patient Preference and Adherence is an international, peer-reviewed, open access journal that focuses on the growing importance of patient preference and adherence throughout the therapeutic continuum. Patient satisfaction, acceptability, quality of life, compliance, persistence and their role in developing new therapeutic modalities and compounds to optimize

\section{Dovepress}

clinical outcomes for existing disease states are major areas of interest for the journal. This journal has been accepted for indexing on PubMed Central. The manuscript management system is completely online and includes a very quick and fair peer-review system, which is all easy to use. Visit http://www. dovepress.com/testimonials.php to read real quotes from published authors. 